\title{
Análisis de Twitter como fuente, recurso de interacción y medio de difusión para los periodistas vascos
}

\section{Iturri, elkarreraginerako baliabide eta hedabide gisa, Twitter-ek euskal kazetarientzat duen garrantzia aztertzea}

\section{Analysis of Twitter as a newsfeed, interaction resource and diffusion tool for Basque journalists}

\section{Mikel Garcia ${ }^{1}$}

Carmen Marta-Lazo²

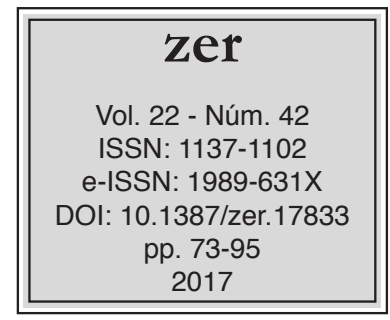

Recibido el 14 de abril de 2016, aceptado el 31 de octubre de 2016.

\section{Resumen}

El objetivo del presente estudio es descubrir el valor, la influencia y el uso de la red social Twitter como herramienta periodística entre los profesionales vascos de la comunicación. Se ha analizado el uso de Twitter por parte de los comunicadores de los cinco periódicos generalistas más vendidos y leídos del País Vasco: El Correo, El Diario Vasco, Deia, Gara y Berria.

Palabras clave: Periodismo, periodista, redes sociales, Twitter, País Vasco.

\section{Laburpena}

Ikerketa honen helburua da Twitter sare sozialak komunikazioaren euskal profesionalen artean kazetaritzarako tresna gisa duen balioa, eragina eta erabilera aztertzea. Euskal Herriko bost komunikabide jeneralista salduenek eta irakurrienek (El Correo, El Diario Vasco, Deia, Gara eta Berria) Twitter nola erabiltzen duten aztertu da.

Gako-hitzak: Kazetaritza, kazetaria, sare sozialak, Twitter, Euskadi.

UNED,mgidiakez@gmail.com

2 Universidad de Zaragoza, cmarta@unizar.es 


\begin{abstract}
The aim of this study is to discover the value, influence and the use of social network Twitter as a journalistic tool among Basque communication professionals. To this end, it has analyzed the use of Twitter by the journalists of the five best selling and most widely read newspapers in the Basque Country: El Correo, El Diario Vasco, Deia, Gara and Berria.
\end{abstract}

Keywords: Journalism, journalist, social networks, Twitter, Basque Country. 


\section{Introducción}

La información y la comunicación son la base de nuestra sociedad actual y es fundamental entender cómo crean y difunden esa información los profesionales que la manejan. En concreto, la presente investigación intenta resolver cómo repercute la red social Twitter en ese flujo, no solo a la hora de crear, transformar y difundir la información, sino también a la hora de entender el propio proceso comunicativo. Como pregunta de investigación nos planteamos: ¿cuál es la función que juega Twitter en la labor comunicativo-informativa de los periodistas que trabajan en los principales periódicos vascos?

Los ciudadanos recurren asiduamente a las redes sociales para informarse, según aseguran varios estudios estadounidenses recopilados en How social media is replacing traditional journalism as a news source (2012). Asimismo, los estudios de Digital Journalism Study (Oriella PR Network, 2011 y 2013) confirman que Twitter es la red social que más se ha desarrollado como herramienta profesional entre los periodistas.

Algunas investigaciones han demostrado que los medios cada vez utilizan más esta red para difundir noticias (Kwak, Lee, Park \& Moon, 2010; Eford, Linke \& Messner, 2011; Broersma \& Graham, 2013; Vis, 2013). Otros estudios destacan el interés de Twitter como fuente (García De Torres et al., 2011; Cobos, 2011) y como medio para interactuar sobre contenidos informativos con la audiencia (Doval, 2014; Oviedo Anchundia \& Ulloa, 2016).

En España, más de once millones de personas al mes visitan Twitter (ComScore, 2016; GAD, 2012), lo que corrobora que los ciudadanos utilizan cada vez más esta red social para seguir los medios de comunicación (Campos, 2008; Noguera, 2010; Herrera \& Requejo, 2011). De los 132 periodistas entrevistados en El periodista en la encrucijada (Diezhandino, 2012), el 91,6\% opina que Internet y las redes sociales cambian el papel del periodismo como intermediario entre la realidad y el receptor, y el 100\% cree que Internet está modificando el sistema de acceso a las fuentes del periodismo.

\section{Metodología}

Para la elaboración de esta investigación, se han realizado entrevistas en profundidad a cinco periodistas que ocupan el cargo de redactores jefe o cabezas de sección de diferentes apartados, uno de cada periódico: Alain Laiseka, responsable de Deportes en Deia; Mikel Lizarralde, jefe de Cultura en Berria; Encarni Bao, responsable de Mundo en El Correo; Ane Arruti, responsable de Cultura en Gara; y Antxon Blanco, redactor jefe de El Diario Vasco. Las entrevistas son estructuradas, con un guion que analiza los mismos aspectos en todos los casos. Además, para comparar los resultados, se ha llevado a cabo un análisis de contenido de los tweets que han recibido y enviado y de las interacciones que han tenido otros veinticinco periodistas (cinco periodistas de cada periódico) a lo largo de un mes. En concreto, se eligió el mes de mayo de 2014, por ser un mes no estival y sí noticioso (coincidió con acontecimientos como las elecciones europeas o el fin de la liga de fútbol, y seguían en activo conflictos como el de Ucrania). 
La dificultad, en algunos casos, ha consistido en saber discernir si el mensaje es informativo o de opinión. Algunas informaciones, al fin y al cabo, llevan implícita la opinión, una intencionalidad clara, aunque quizá no de manera explícita. Sin embargo, si llevamos este enfoque al extremo, no hay información aséptica y objetiva: detrás de un tweet, siempre hay una elección (informar sobre ese hecho en concreto), siempre hay una perspectiva. Y detrás de no pocas opiniones, también hay mucha información. Por ello, se ha considerado mensaje informativo aquel que no contiene una valoración explícita sobre la información que se da y se ha creado una tercera categoría con el objetivo de aportar unos resultados más exhaustivos y precisos: la función de informar opinando. Es decir, aquellos mensajes que contienen, de manera equilibrada, un fuerte tono tanto informativo como valorativo (por ejemplo, dando una información y calificándola o poniéndole un adjetivo).

En resumen, se ha analizado la información de un total de treinta redactores de los diferentes periódicos que conforman el mapa de la prensa vasca más leída.

\section{Análisis de resultados}

\subsection{Perfiles}

De los treinta periodistas elegidos, ocho son mujeres y la edad de la muestra es amplia, ya que va desde periodistas que tienen menos de treinta años hasta los que tienen más de cincuenta. El 87\% de los profesionales utilizan Twitter desde hace más de un año; el 77\% lo emplean varias veces al día y lo hacen sobre todo profesionalmente. 7 de 30 no emplean la red social con tanta frecuencia.

Como afirma Bao sobre los redactores del periódico El Correo, "hay algunos convencidos desde la primera hora y otros que aún no se han asomado". Calcula que más del $50 \%$ de los profesionales de su periódico utilizan Twitter. La cifra es más alta en los demás periódicos, según los entrevistados: Blanco estima que el 70\% de los periodistas de El Diario Vasco emplean la red social, que ésta "ha calado" y que los periodistas "hacen un uso frecuente de Twitter". En opinión de Lizarralde, en Berria "casi todos tienen cuenta en Twitter", aunque apostilla que existen grandes diferencias en el uso por parte de los compañeros, puesto que "algunos lo utilizan obligados por el trabajo y otros de manera mucho más libre". En Deia " "creo que todo el mundo usa Twitter ahora, salvo los muy veteranos. Los jóvenes y los de mediana edad lo usan", afirma Laiseka. La respuesta de Arruti sobre la cantidad de redactores que utilizan Twitter en Gara es más vaga, aunque sostiene que "en la redacción la cantidad de usuarios va en aumento, diría que en general ha calado bien, por voluntad de los periodistas".

En resumen, la mayoría utiliza Twitter y ese uso aparece ligado al trabajo: muestra de ello es la presentación que realizan de sí mismos en sus respectivas cuentas. Los treinta se definen como periodistas en sus cuentas de Twitter, por lo que se presupone que harán un uso de la herramienta como periodistas. De hecho, el resto de la presentación y datos que se ofrecen son profesionales: el 77\% da el nombre del medio para el que escribe, y el $43 \%$ añade el enlace al medio o al blog que tiene en el medio, o señala la cuenta que tiene en Twitter dicho medio. La identificación con el medio empieza para algunos desde la propia fotografía, incluyendo por ejemplo 
el logo del medio, o desde el nick (como es el caso del director de Gara Iñaki Soto, @ gara_isoto). Todo ello refleja una estrecha relación del periodista con el periódico, dejando claro desde dónde se escribe y dando a entender que se hará un uso de Twitter como periodista y como miembro de un periódico concreto.

Más de la mitad (el 53\%) especifican sobre qué "hablarán" en la red social. Dicho de otro modo, detallan su cargo en el medio o la sección para la que escriben, dejando entrever que es el área que cubren. En algunos casos, la propia fotografía o avatar gira en torno a esa área que cubren en el periódico y que es también carta de presentación en Twitter, sobre todo en el caso de los periodistas de Deportes. Muchos de los seguidores de estos perfiles buscarán justamente lo que ofrecen como periodistas de un determinado medio y una determinada sección, y los periodistas actuarán en la red social en consecuencia.

Figura 1. Perfiles en Twitter de tres de los periodistas analizados.

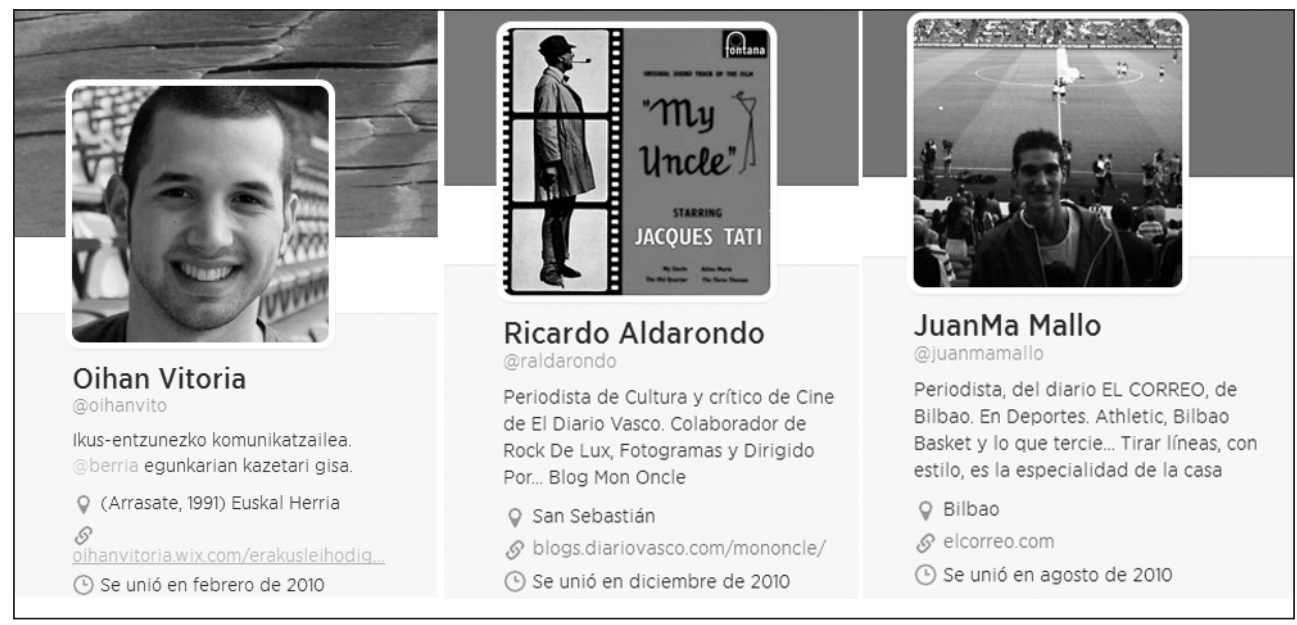

Fuente: Twitter.

\subsection{Usos}

El uso de Twitter de manera profesional, aunque mayoritario, no es el único entre los redactores. Entre los periodistas entrevistados, tres de los cinco cuestionados asumen su cuenta como una mezcla entre personal y profesional, una cuarta persona dice que es "sobre todo una cuenta personal, a la que doy uso profesional", y el quinto la describe como cuenta exclusivamente profesional. En cualquier caso, el rasgo profesional está muy presente y prevalece entre los entrevistados. En lo que respecta al análisis de la actividad tuitera de los veinticinco periodistas restantes, se han tenido en cuenta únicamente los tweets profesionales de dichos redactores y se han descartado los considerados no profesionales. De todos modos, se repite el mismo esquema que con los entrevistados. Es decir, hay una mezcla de tweets profesionales y no profesionales, pero sobresale de manera clara el uso profesional de la red social. En concreto, el $83 \%$ de los mensajes enviados por los periodistas es de tinte profesional. El $17 \%$ restante le sirve al periodista, por ejemplo, para protestar 
o denunciar alguna injusticia, pedir solidaridad con algún colectivo, ironizar sobre hechos de actualidad, reivindicar causas que considera justas... y son una pieza clave, en tanto que van definiéndolo como persona y como profesional, dejan entrever los valores y principios sobre los que se sustenta el que escribe, y el comunicador va construyendo así su perfil y su marca personal-profesional. La cuenta del periodista no es la cuenta oficial del medio y, por ello, se puede permitir ese tipo de mensajes y ese tipo de "libertades", que ayudan a contextualizar a la persona que hay detrás del profesional y que lo hace más cercano a la comunidad de lectores que lo siguen. Es más, algunos de los tweets no profesionales también ayudan a mantener el contacto con las fuentes, a interactuar con el resto de usuarios o a estrechar lazos profesionales de una manera más informal.

Figura 2. Ejemplo de un tweet no profesional de un periodista.

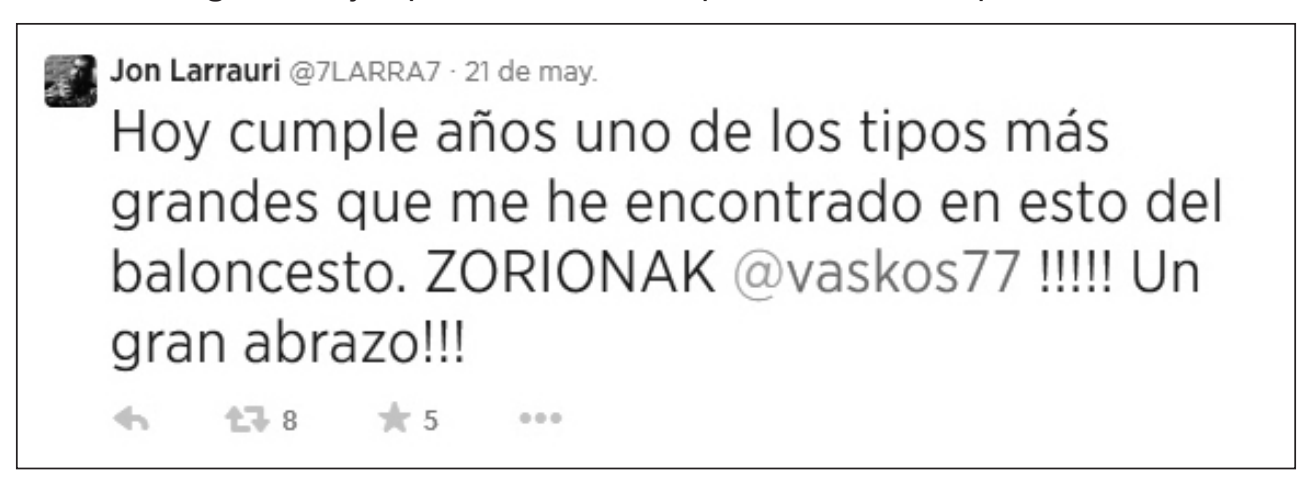

Fuente: Twitter (21 de mayo).

De aquí en adelante, sólo se consideran los mensajes y los datos de los tweets profesionales. Entre los usos profesionales de Twitter, destaca el empleo de la red social como fuente periodística. Entre los entrevistados, todos subrayan que se informan a través de Twitter y que ése es, además, el principal o uno de los principales usos que le dan. Entre los periodistas no entrevistados, este uso no es tan apreciable a simple vista, puesto que al ser, digamos, un uso pasivo del periodista, no se registra tan fácilmente en su timeline. Sin embargo, el valor de Twitter como fuente es indiscutible cuando es la propia fuente (una entidad, una persona...) la que ofrece la noticia en Twitter (una primicia, una confirmación, un desmentido, un comunicado...) y el periodista reenvía dicho mensaje, haciéndose eco del mensaje original que ha leído (y le ha servido como fuente) en la red social.

Tres de los encuestados también añaden entre los usos de la red social la de testear el interés de la información. Además de fuente, la herramienta se convierte así en un termómetro del interés público y de los contenidos que elabora el periodista. Una vez más, al ser un uso pasivo, a través del análisis de los tweets lo intuimos, pero es difícil detectarlo, aunque es posible, como se muestra en la siguiente captura. 
Figura 3. Twitter sirve para testear el interés de los lectores.

Ricardo Aldarondo @raldarondo.23 de may.

Por el número y velocidad de los RT y FAV deduzco que la opinion de SILS MARIA de Olivier Assayas era de las q más deseábais de \#Cannes2014

Fuente: Twitter (23 de mayo).

La consulta es otro uso bastante extendido entre los periodistas y muestra, una vez más, el uso de Twitter como fuente. Los profesionales aprovechan la red social para consultar información y datos a un contacto en particular, o bien en general. Tres de los cinco entrevistados afirman emplear Twitter para ello.

Figura 4. El periodista consulta información a sus seguidores.

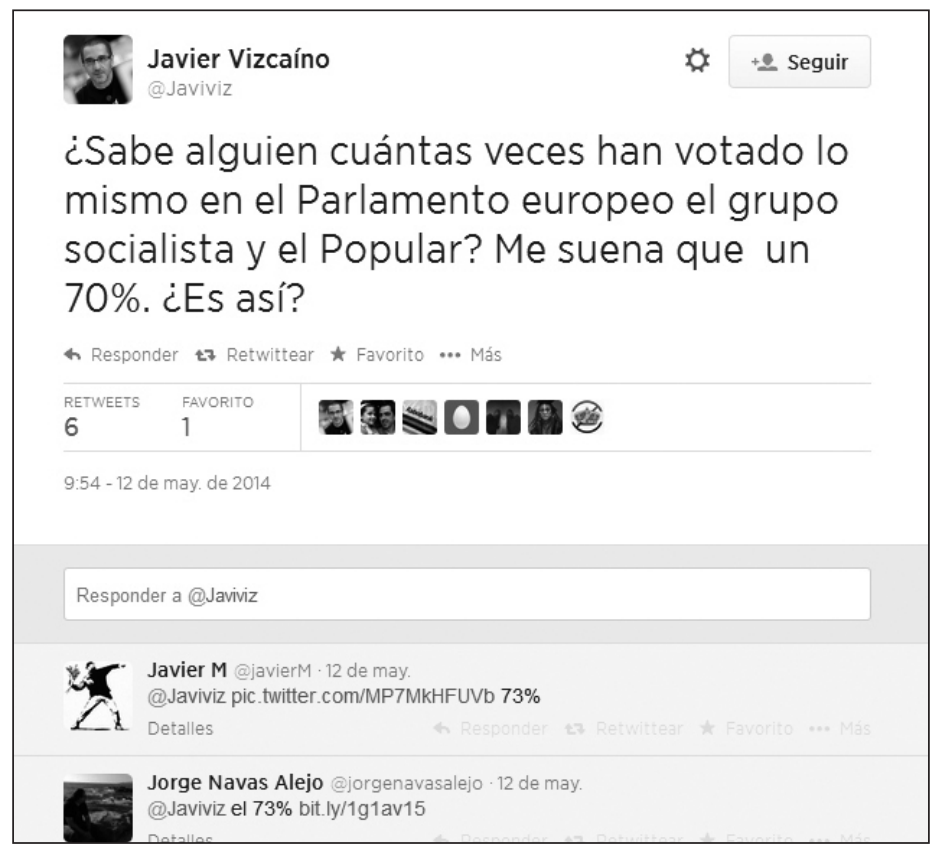

Fuente: Twitter (12 de mayo).

Una función destaca especialmente: difundir contenidos con enlace. La difusión puede ser de tres tipos: con enlace a un artículo propio, con enlace a un contenido del medio del que se es parte (escrito por algún compañero de periódico) o con enlace a un contenido externo, que no tiene que ver con el medio al que pertenece el periodista. Entre los entrevistados, excepto Alain Laiseka, que utiliza Twitter de manera pasiva (solo para informarse), el resto incluye entre los usos la difusión de contenidos 
con enlace a contenidos propios, del medio o ajenos. En lo que respecta a las cuentas analizadas, es la función más extendida: un 32\% de todos los mensajes profesionales publicados por los veinticinco redactores están dedicados a la difusión de contenidos a través de la red social, incluyendo el enlace a la página donde se desarrolla más profusamente el contenido presentado en 140 caracteres. Para los profesionales de la comunicación, la red social es un buen modo de ofrecer y recomendar contenidos, aprovechando la capacidad expansiva de Twitter para llegar a un espectro amplio de usuarios. Como cabría esperar, los contenidos a los que redireccionan los redactores tienen que ver muchas veces con el área periodística que cubren. La función de filtro o función rastreadora del periodista está muy presente, ya que selecciona y elige aquellos contenidos que le parecen interesantes para sus seguidores, los presenta en Twitter con un enlace y posibilita que los usuarios, que quizá de otra manera no hubieran accedido a dichos contenidos, entren en ellos.

El $11 \%$ de todos los mensajes están dedicados a la difusión de contenidos con enlace a artículos del propio periodista; el $9 \%$ son contenidos de algún compañero del medio; y el 11\% son contenidos desarrollados en otros medios o en otras páginas web que no tienen que ver con el periódico en el que trabaja el redactor. Si sumamos la difusión de los contenidos propios y los de los compañeros, resulta que el $20 \%$ de todos los mensajes enviados por los veinticinco profesionales son enlaces que llevan al usuario a algún contenido del periódico. Lo cual refleja que, además de recomendar a los demás los contenidos seleccionados en la red por el periodista, la difusión de contenidos también cumple una función de promoción. En cualquier caso, los periodistas no descuidan el $9 \%$ dedicado a la difusión de contenidos ajenos (ni el $68 \%$ de mensajes dedicados a otras funciones que no sean la difusión de contenidos), porque si no, resultaría demasiado evidente el uso de la red social como instrumento para el autobombo y la autopromoción, y el periodista perdería credibilidad.

Según lo analizado, entre los mensajes destinados a la difusión de contenidos con enlace no hay ni un solo tweet que no vaya acompañado de una presentación o gancho sobre el contenido al que se redirecciona. El gancho o el texto puede ser informativo o de opinión y los hay muy variados. En general, es muy socorrida la presentación del contenido con un toque de opinión, que deja clara la postura del periodista respecto al tema o contenido en cuestión; también se suele entresacar una parte del contenido al que se enlaza, por considerarlo llamativo o reclamo; o bien se ensalza o desprecia el contenido; o se crea expectación y curiosidad al respecto. Tener éxito depende, en cierta medida, de la habilidad de los periodistas para controlar el lenguaje y los recursos propios de la red social.

No se puede hablar de la importancia que tiene la difusión de contenidos en Twitter sin tener en cuenta una realidad: tres de los cinco periódicos a los que pertenecen los profesionales elegidos son periódicos que ofrecen en Internet parte de sus contenidos encriptados o previo pago (El Correo, El Diario Vasco y Gara). La consecuencia es que algunos mensajes de los redactores pertenecientes a estos medios enlazan a contenidos propios o de compañeros que no son totalmente abiertos, si no que contienen algunas líneas o un párrafo, el comienzo del artículo, y después hay que registrarse o directamente acudir a la versión en papel para leer el resto del contenido (aunque en su defensa hay que subrayar que la mayoría de los contenidos enlazados por estos periodistas son totalmente abiertos). En principio, no parece que 
tenga mucho sentido ofrecer el enlace a un contenido que está a medias, pero quizá no han encontrado una manera mejor de mostrar dicho contenido. Otros sí lo han hecho, y son varios los periodistas que se han atrevido a difundir los contenidos de sus periódicos valiéndose, a falta de enlace (por ser contenidos cerrados), del ingenio para difundir los contenidos encriptados por otras vías a través de la red social. Los contenidos difundidos sin enlace representan el $1 \%$ de todos los mensajes analizados, pero todos los periodistas que han hecho uso de esta función pertenecen a los tres periódicos que no tienen todos sus contenidos en abierto.

Figura 5. No todos los medios ofrecen sus contenidos en abierto en internet.
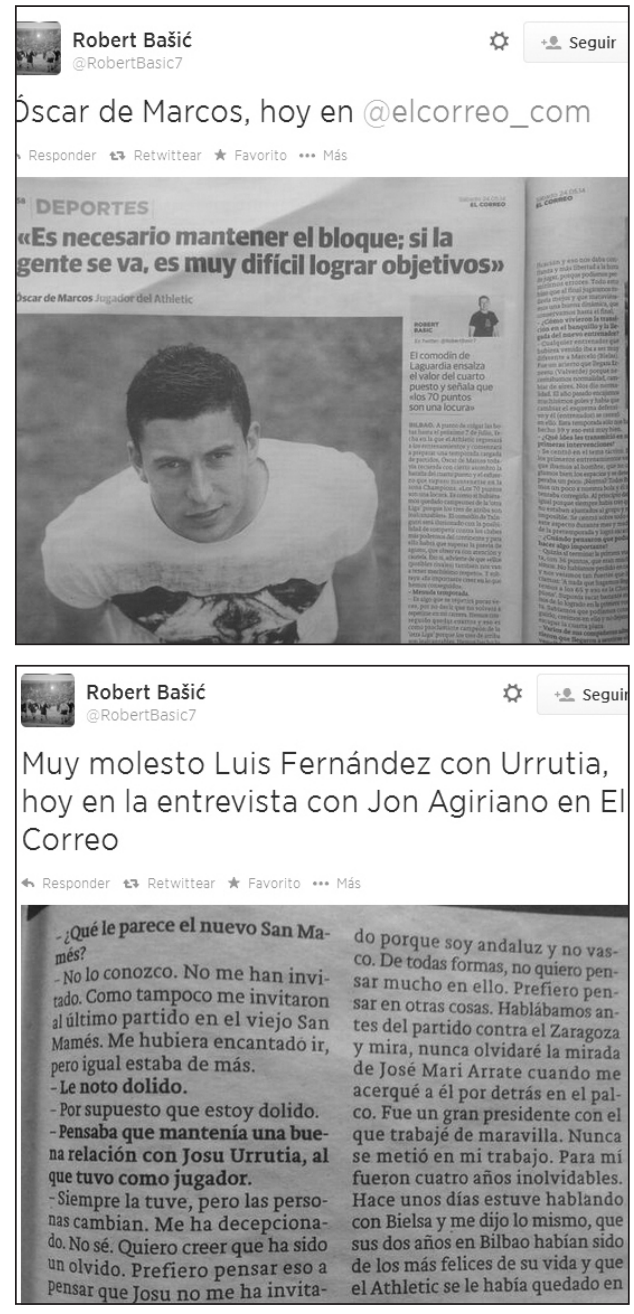

Fuente: Twitter (24 de mayo y 5 de mayo).

Las prácticas mencionadas se parecen a otra función encontrada en las cuentas analizadas, función que también ha sido reconocida por tres de los periodistas entrevis- 
tados. Es más, uno de ellos, Ane Arruti, afirma que es uno de sus usos prioritarios: la promoción del medio al que pertenece. La promoción se puede realizar de muchas maneras, por supuesto promocionando los contenidos, pero también apelando por ejemplo a los valores del medio, al trabajo del equipo que lo conforma, a motivos extra-periodísticos que pueden incitar al lector a comprar el periódico, a novedades en la redacción, a la comunidad que rodea el medio... Esta función de promoción del medio abarca el $4 \%$ de todos los mensajes de las veinticinco cuentas analizadas.

Figura 6. Tweet promocional.

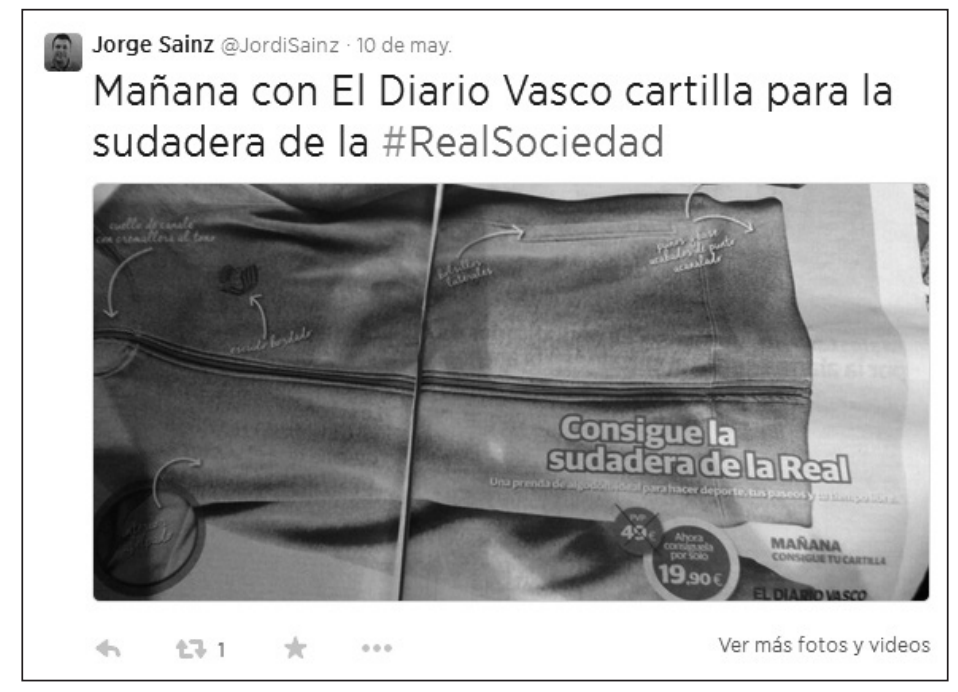

Fuente: Twitter (10 de mayo).

Añadimos que, aunque la difusión de contenidos con enlace es la función más repetida en Twitter, la red social demuestra al mismo tiempo que, como herramienta comunicativo-informativa, no es dependiente de otros medios; es decir, que también funciona con suficiente autonomía como para informar, opinar, hacer análisis e incluso artículos sin necesidad de enlazar a otras páginas en las que se desarrolle todo ello. De hecho, el $68 \%$ de todos los mensajes profesionales analizados, en tanto que no contienen un enlace, así lo atestiguan.

Tras la difusión de contenidos, la función más frecuente entre los periodistas vascos es la de ir informando de algún acontecimiento o evento en directo. Mensajes breves y concisos, instantáneos y a modo de RSS o noticiero, la red social da el perfil óptimo para este uso. No olvidemos que Twitter también es accesible desde los dispositivos móviles inalámbricos (como ordenadores portátiles, ipads, tablets o teléfonos inteligentes) y que por lo tanto, desde la ubicuidad que ofrecen hoy en día todos estos dispositivos, la red social es un importante aliado del periodista para informar de lo que está pasando desde cualquier lugar, en cualquier momento. En concreto, en lo que respecta a los entrevistados, todos excepto Laiseka (que, recordemos, utiliza Twitter solo para informarse) emplean la red social para ir informando de algún hecho según está pasando. Entre los no entrevistados, únicamente tres no 
utilizaron en el mes de mayo la red social para ir informando y/u opinando sobre lo que está ocurriendo. Es decir, un $88 \%$ hicieron uso de esta función y en total, un $19 \%$ de todos los mensajes enviados estuvieron dedicados a ir contando en directo lo que acontece. Los periodistas han cubierto acontecimientos de muy diversa índole y sección, aunque según la noticia, evento o hecho al que se le hace el seguimiento, éste suele presentar diferentes estilos y características (observar la figura 7). Queda patente que, si bien elementos de Twitter como el hashtag, la fotografía o el retweet juegan siempre un papel muy relevante, están si cabe más presentes en esta función. Al fin y al cabo, para ir contando lo que acontece, las aportaciones de los que lo están viviendo de primera mano son un valor añadido importante.

Los tweets dedicados a ir contando lo que acontece se han dividido en dos grupos: los tweets informativos y los tweets que incluyen opinión y comentarios. El resultado es que un $12 \%$ de todos los mensajes analizados informan de algún acontecimiento a tiempo real y que el $6 \%$ van informando del evento a través de opiniones y comentarios. En general lo que se ha observado es que el seguimiento no es puramente informativo o puramente valorativo, sino una combinación de ambos. Los periodistas dan cuenta de lo que está pasando sobre todo informando y aportando datos y novedades "objetivas", y van intercalando, de vez en cuando y en menor medida, análisis, opiniones y valoraciones al respecto.

Figura 7. Seguimiento de dos eventos diferentes.

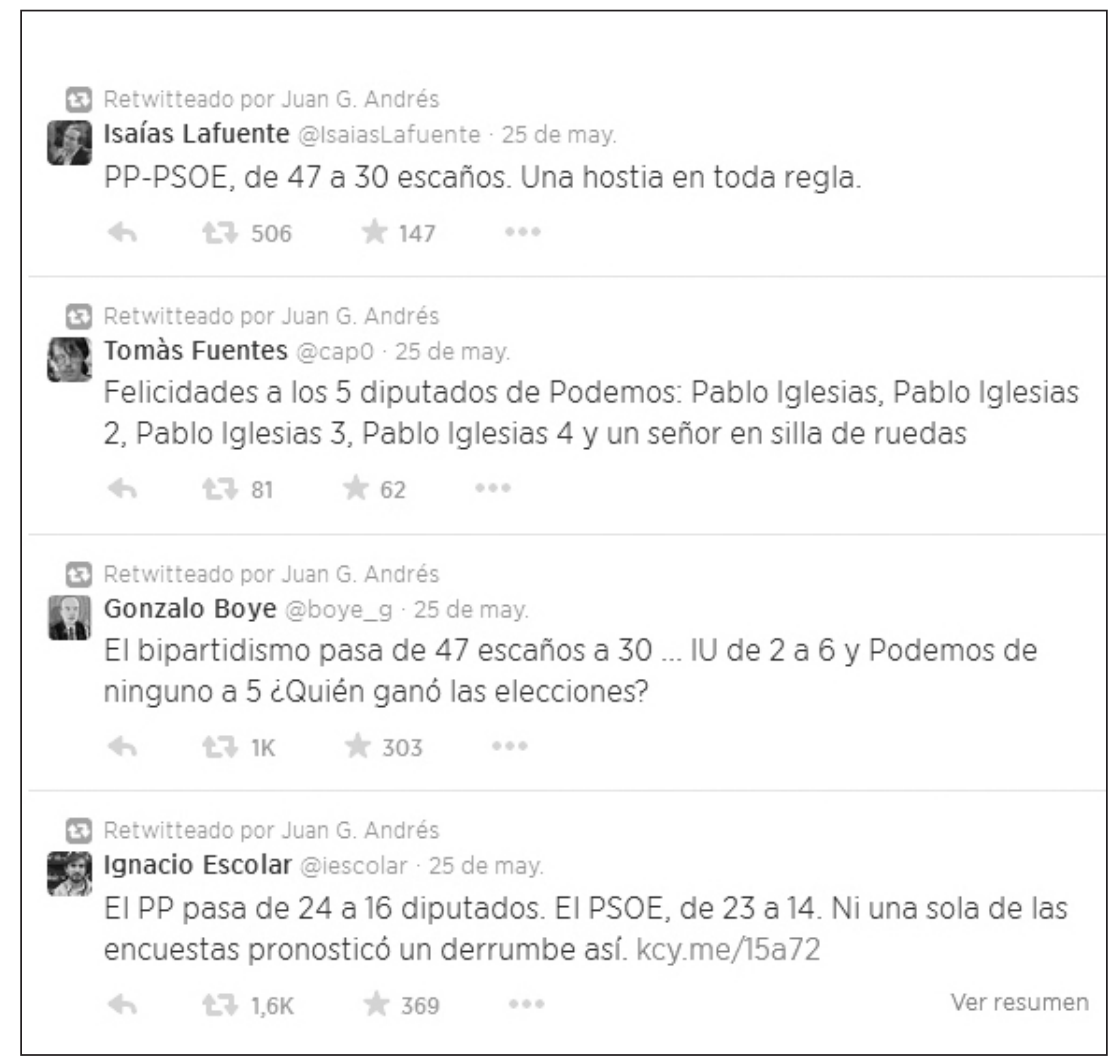




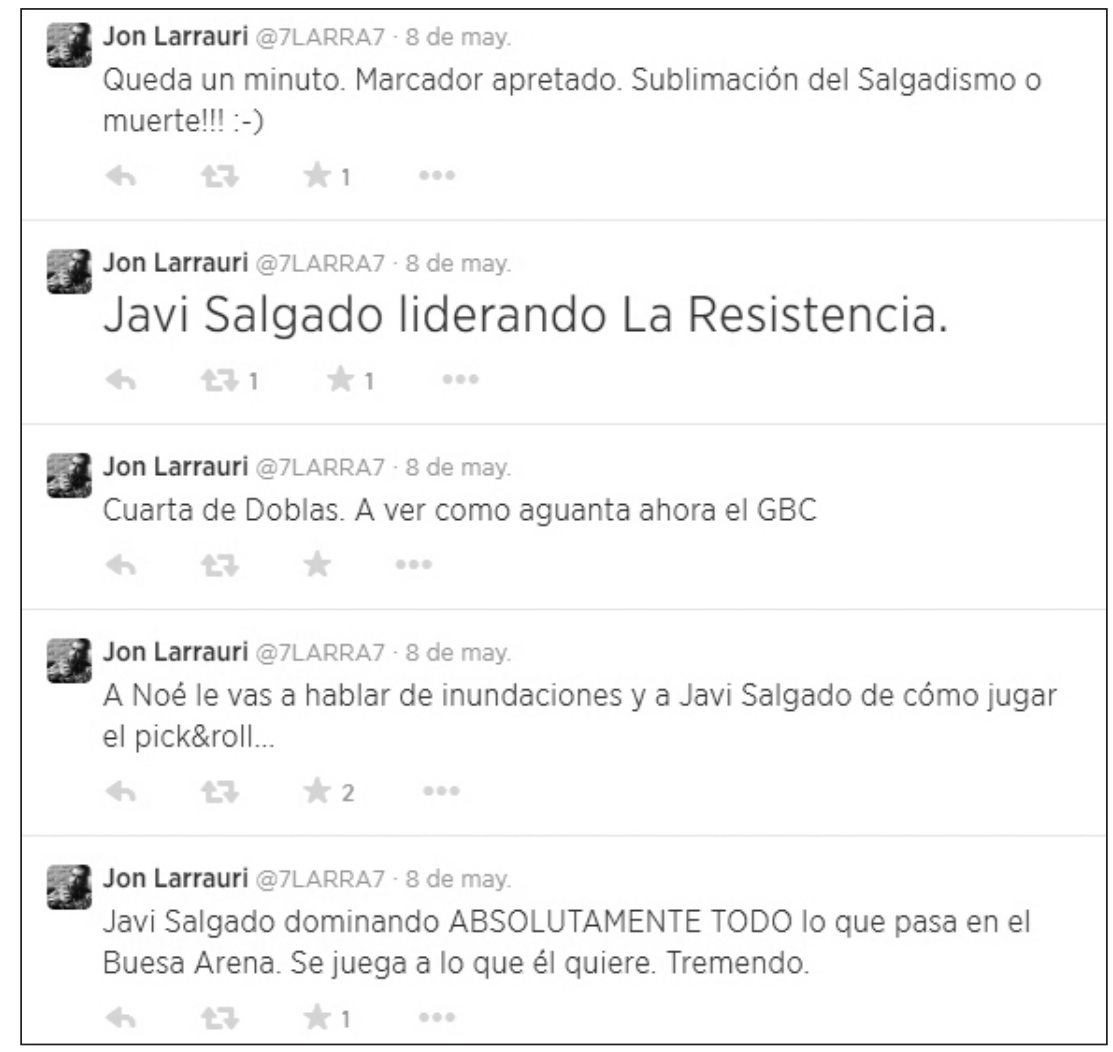

Fuente: Twitter (25 de mayo y 8 de mayo).

Esta función da repetidas muestras de Twitter como herramienta colaborativa, ya que el acontecimiento lo van contando y completando diferentes usuarios, se va desarrollando desde diferentes perspectivas, y unos y otros se hacen eco (a través del retweet) de los mensajes de los demás. Al periodista, los mensajes de los demás actores implicados en el acontecimiento o de los demás informantes le sirven como fuente.

Tras el uso de la red social para informarse, la difusión de contenidos y la cobertura de acontecimientos en tiempo real, las funciones que más se repiten son informar y opinar. Ambos aparecen entre los usos descritos por tres de los cinco entrevistados. Entre las veinticinco cuentas analizadas, esta función también cuenta con una notable presencia. Solo hay una persona (Olatz Barriuso) que no empleó en mayo la red social para informar, y solo dos no opinaron en Twitter durante ese mes (Olatz Barriuso y Tamara de la Rosa, ambas con una frecuencia de uso muymuy baja).

En las veinticinco cuentas examinadas, información y opinión se mezclan, se intercalan y conviven habitualmente en Twitter. Hay mensajes que aúnan información y opinión, hay mensajes que sobre todo informan y mensajes en los que sobre todo se opina, pero no son para nada tratamientos separados, sino mensajes que se complementan. 
Figura 8. El primer mensaje informa sobre el hecho, el segundo opina sobre el mismo. Ambos tweets se complementan y contextualizan la noticia.

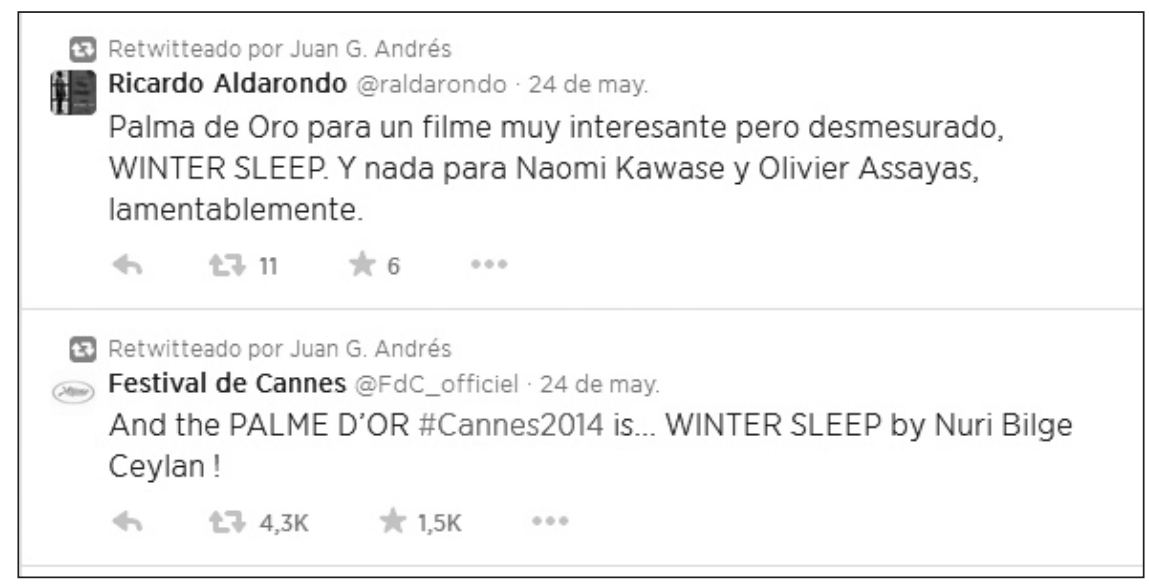

Fuente: Twitter (24 de mayo).

Los porcentajes de unos y otros mensajes son parecidos. El 14\% de todos los mensajes enviados por los veinticinco periodistas están dedicados a informar, el $10 \%$ a enviar tweets que aúnan información y opinión, y un 9\% a opinar. Pero ese $9 \%$ se convierte en un $13 \%$ si sumamos los mensajes dedicados a debatir. Aunque los tweets en los que el periodista crea o participa en debates se han analizado por separado por su relevancia (cuantitativa y sobre todo cualitativa), debatir no deja de ser una forma de expresar la opinión sobre una noticia o sobre la actualidad y, por lo tanto, también podemos integrarlos sin problema en los mensajes dedicados a opinar. Los periodistas opinan de manera muy clara y sin medias tintas. Con la profesionalidad que les exige su perfil de periodistas, pero sin el corsé de ser una cuenta oficial (la del medio, por ejemplo) o de escribir para un artículo en el que la subjetividad y la opinión personal tiene mayores límites, Twitter parece una herramienta propicia para que los periodistas se expresen sobre la actualidad no solo informativamente, sino también dando su opinión personal y profesional. Además del humor (muchas veces a modo de crítica humorística), la denuncia y la crítica están muy presentes en Twitter. Los periodistas opinan sobre temas candentes con contundencia, a veces de una forma que no se podría hacer desde la cuenta oficial del periódico, porque se mueve en uno márgenes más constreñidos, pero estos mensajes ayudan también al propio medio, creando una comunidad a su alrededor. Al fin y al cabo, por una parte a los profesionales les sirve para construir su personaje y su marca y para trabajar sobre los valores y principios que defienden y, por otra, compartir una misma escala de valores une a los lectores en torno al periodista y por ende en torno al medio, reforzando el sentimiento de pertenencia a una comunidad con los mismos principios. Otro tipo de opinión es aquella opinión cualificada que también busca el lector.

Por otra parte, la opinión da pie muchas veces a la interacción con el resto de usuarios. Al interpelar a emociones, sentimientos y valoraciones con las que otros se sienten identificados o bien no comparten, los usuarios muestran la necesidad de responder y dar su punto de vista. 
Aquellos mensajes que expresamente tienen la intención de crear un debate en torno a un tema o que son parte de un debate sobre alguna cuestión suponen el 3\% de todos los tweets y es una función a la que recurren el $80 \%$ de los periodistas no entrevistados. El feedback es directo y la interacción une a los periodistas y a sus lectores en un intercambio (en teoría) horizontal. La accesibilidad y el contacto entre unos y otros es fundamental, tanto para unos como para otros: el debate es un uso muy interesante para abrir la puerta al lector (para acercarse al periodista y al medio) y para activar y mantener viva la comunidad que rodea al periódico en cuestión. Asimismo, para el comunicador es una oportunidad de recibir nuevas perspectivas y enriquecer su punto de vista (o bien afianzarse en su postura). Cuando el debate gira en torno a un artículo del propio redactor, el artículo gana en repercusión, aumenta el interés por el mismo y puede incluso generar cambios dentro del propio artículo, en función de los comentarios recibidos.

En menor medida, se han detectado otros usos. Los periodistas tienen en cuenta a los lectores de varias maneras, contestando sus dudas, atendiendo sus propuestas o aceptando sus críticas y correcciones (una interacción relevante, en tanto que es una ayuda mutua para que noticias y reportajes se interpreten correctamente e incluyan las posibles mejoras propuestas por los lectores). No solo se tiene en cuenta lo que el lector tiene que decir, los periodistas potencian en Twitter el rol activo del lector. Asimismo, está presente el uso de la red social para contactar con alguien. Dos de los cinco entrevistados lo incluyen entre sus usos y también ha sido detectado en más de una ocasión durante el análisis de los timelines. El contacto no es siempre concreto; lo vemos en las siguientes capturas:

Figura 9. Dos periodistas intentan contactar con perfiles concretos para sus reportajes.

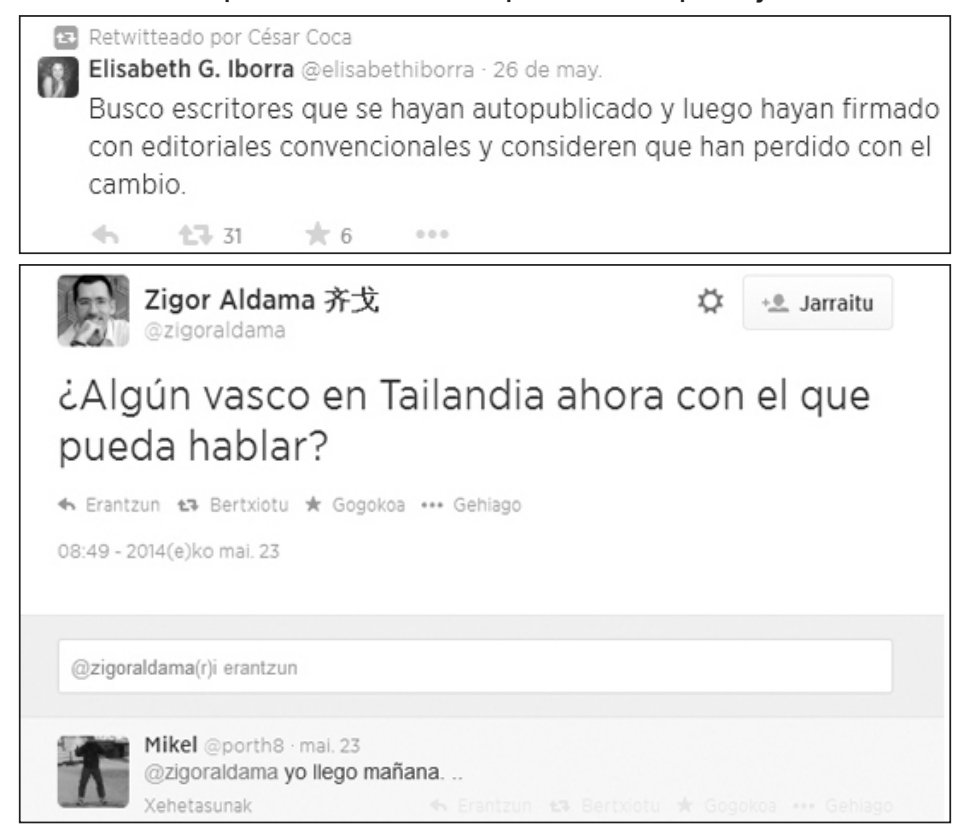

Fuente: Twitter (26 de mayo y 20 de mayo). 
Twitter también sirve para informar a los lectores sobre cuestiones relacionadas con el medio, aunque sean extra-periodísticas, como por ejemplo cuando el director de Gara informa de que han tenido una avería en rotativa y el periódico aún no ha llegado a algunos quioscos.

El porcentaje de los principales usos detectados en los mensajes profesionales de las veinticinco cuentas analizadas se puede resumir de manera gráfica en el siguiente gráfico:

Gráfico 1. Usos detectados en Twitter.

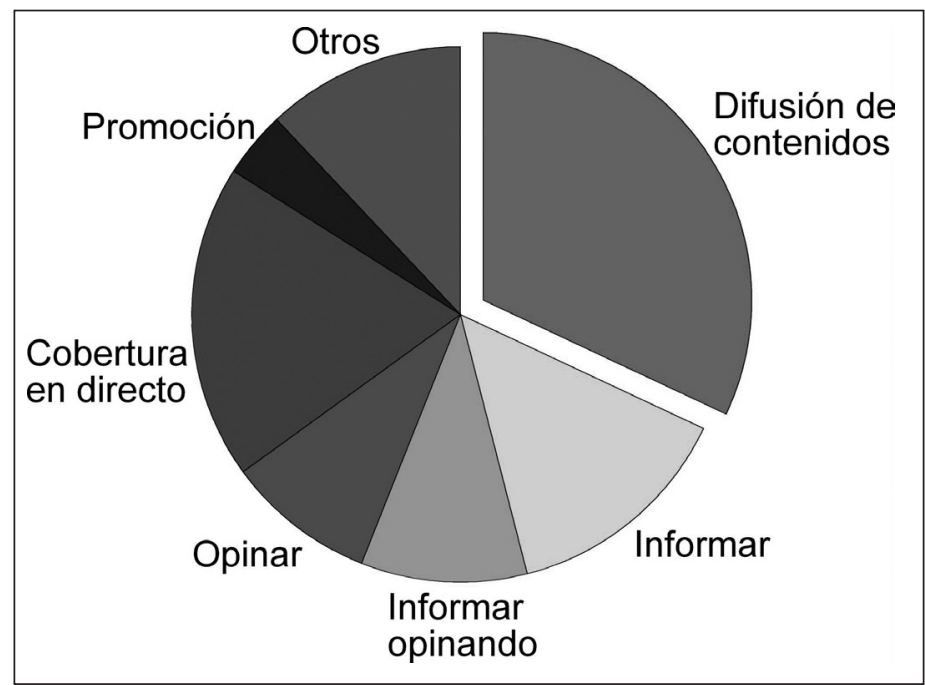

Fuente: Elaboración propia.

\subsection{Recursos}

La posibilidad de adjuntar fotografías e imágenes en los mensajes es aprovechada por los periodistas. De los veinticinco profesionales cuyas cuentas se han analizado, solo una persona no utilizó ninguna imagen en alguno de sus tweets durante el mes de mayo. El $17 \%$ de todos los mensajes de los veinticinco periodistas contienen alguna imagen adjunta. Los datos muestran que la mayoría de mensajes que envían los comunicadores son mensajes escritos (con o sin enlace adjunto) y sin imagen, pero que intercalan tweets con fotografía cuando así lo requiere el mensaje, es decir, cuando verdaderamente la imagen aporta algo al mensaje y no es un simple elemento decorativo. Funciona como información adicional al texto o incluso como información en sí misma, como documento gráfico de lo que está sucediendo (sobre todo para la cobertura de acontecimientos en directo), como instrumento de opinión, como recurso para difundir contenidos sin necesidad de enlazar a otra web (posibilitando así una mayor independencia a la red social) o como muestra de diferentes puntos de vista sobre un mismo hecho.

En cuanto a los favoritos, una vez analizadas las carpetas donde se archivan los mensajes que los veinticinco periodistas han marcado como tal (solo se han tenido en cuenta los favoritos profesionales), la conclusión es que el uso de este recurso es muy 
desigual entre unos y otros. Los favoritos son una especie de guiño: no aparecen en el timeline del periodista, a efectos prácticos, no tienen repercusión (porque no se reenvía ni difunde el mensaje originario), pero es una manera de expresarle a otro usuario que su mensaje ha sido leído y que es de nuestro agrado. Es un modo de mantener el feedback con los demás, de mostrar que lee los comentarios y opiniones de sus lectores, y que reconoce su aportación. Los favoritos analizados así lo demuestran.

En lo que concierne al reenvío de mensajes de otros usuarios, no hay nadie que no haya empleado el retweet. Al igual que ocurre con los favoritos, es también un modo de ser "generoso" en Twitter y difundir y reconocer lo que los demás tienen que aportar. El $41 \%$ de todos los mensajes enviados por los veinticinco redactores son mensajes retuiteados. Cumple una doble función: por una parte, actúa como filtro, en tanto que el periodista decide difundir el mensaje de un tercero y recomendárselo a sus seguidores. Por otra parte, refleja el uso de Twitter como fuente para el profesional de la comunicación, puesto que éste se informa en la red social y después rebota aquello que le ha parecido de interés, otorgando credibilidad a la noticia (o a esa fuente), ya que al reenviarla de alguna manera la da por cierta. Una aportación destacable de los retweets es su uso durante la cobertura de un acontecimiento o hecho en directo. Los periodistas, además de enviar sus mensajes sobre lo que está ocurriendo, también reenvían los de otras personas implicadas y los de otros periodistas u observadores que estén contando lo mismo. La combinación de mensajes propios y ajenos da una visión más amplia y completa de lo que ocurre, y el resultado es un trabajo mejor y con más matices. Por último, es un elemento muy utilizado cuando hay opiniones de por medio. Es decir, el periodista no solo crea opinión con sus propios mensajes, también a través de aquellos mensajes que difunde y que son valoraciones de terceras personas.

Favoritos y retweets son un buen indicador del éxito que ha tenido un mensaje en particular. De todos los mensajes profesionales que los periodistas enviaron durante el mes de mayo, se han separado, de cada timeline de cada periodista, los tres mensajes que obtuvieron más retweets por parte del resto de usuarios y los tres mensajes que tuvieron más favoritos. El resultado es que los mensajes de opinión obtienen los mayores porcentajes. En concreto, el $25 \%$ de los mensajes más retuiteados de los veinticinco periodistas son tweets que tienen como objetivo opinar, y el $26 \%$ de los mensajes con más favoritos tienen la misma función.

Los cinco entrevistados han respondido a la pregunta de si han generado algún hashtag o etiqueta y, excepto Laiseka (que, insistimos, no utiliza Twitter de manera activa), los demás han respondido que sí. Por su parte, solo una de las veinticinco personas cuyos timelines se han analizado no ha utilizado ninguna etiqueta. En concreto, el $21 \%$ de todos los mensajes profesionales enviados por los redactores tienen al menos una etiqueta y es un recurso habitual en la cobertura de acontecimientos en directo. La opinión también está presente en la etiqueta: un hashtag puede ser una manera (jocosa, corrosiva, crítica) de valorar una información o un contenido difundido en el mensaje.

Por último, las menciones son uno de los recursos principales de la red social, puesto que las veinticinco cuentas muestran mensajes mencionando a otros usuarios. El $40 \%$ de todos los mensajes tienen al menos una mención. El uso prolífico de la mención corrobora que la interacción entre periodistas y demás usuarios es frecuente y que se reconoce la aportación de los demás. La mención también es utilizada para señalar el origen de la información, reconociendo así o bien la autoría o bien 
la fuente del contenido divulgado por el periodista. Según lo analizado, el trabajo en equipo, compartir y reconocer es más constructivo y beneficioso en Twitter y, a la larga, más efectivo e inteligente. También sirve, en numerosas ocasiones, como cordón umbilical entre el periodista/contenido del mensaje y el medio para el que trabaja (al incluir la mención del medio en el tweet).

En resumen, de manera gráfica:

Gráfico 2. Porcentaje de los principales recursos detectados.

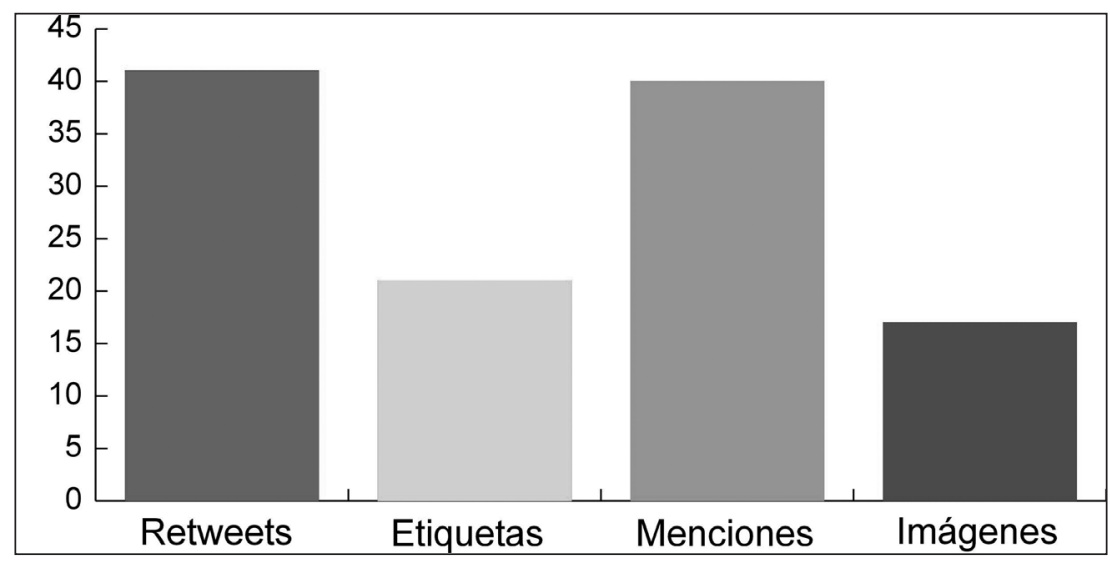

Fuente: Elaboración propia.

Gráfico 3. Porcentaje de los usos profesionales que más retweets han conseguido.

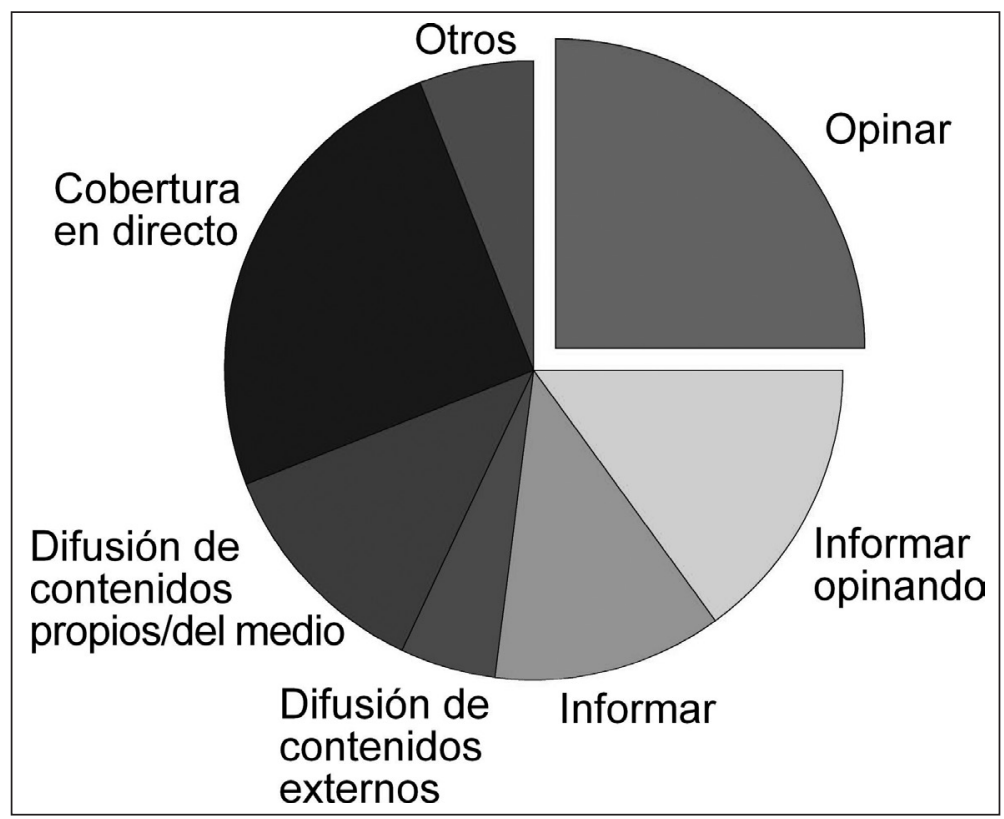

Fuente: Elaboración propia. 
Gráfico 4. Porcentaje de los usos profesionales que más favoritos han conseguido.

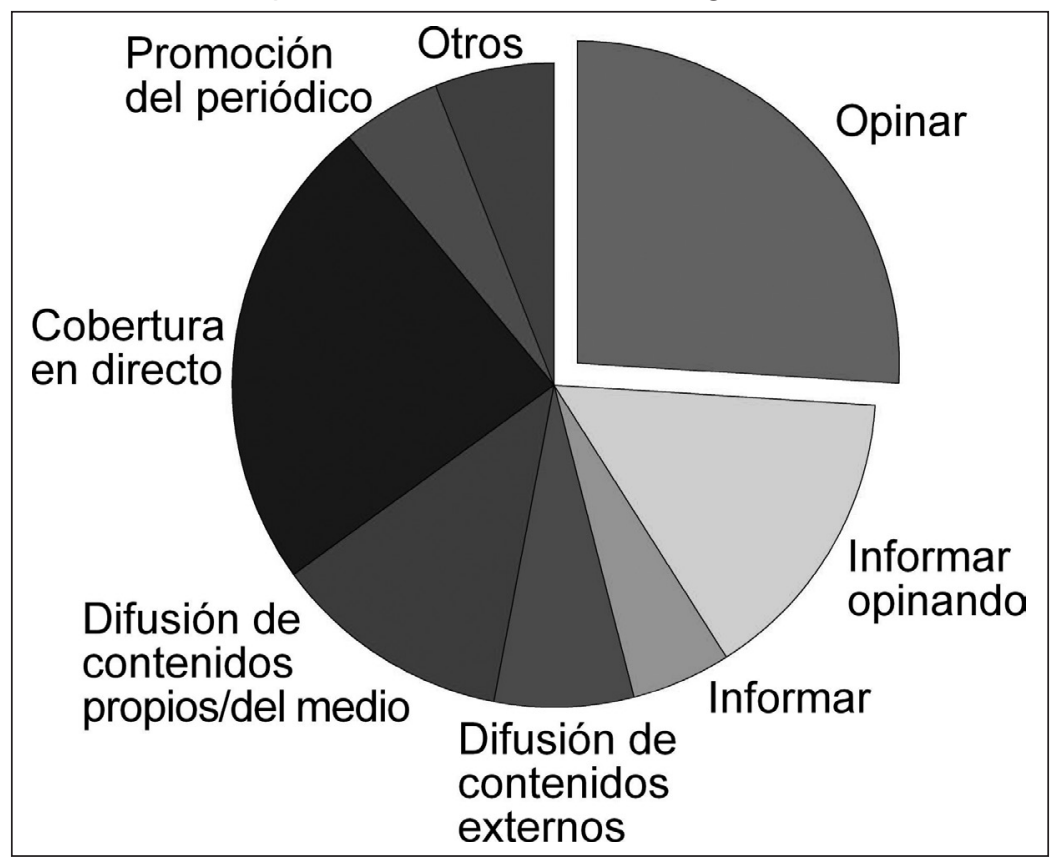

Fuente: Elaboración propia.

\section{Conclusiones}

La mayoría de los periodistas vascos elegidos para esta investigación utilizan Twitter, lo usan frecuentemente y, sobre todo, con objetivos profesionales. Para los periodistas, esta red es fuente de información y opinión. Teniendo en cuenta que las fuentes son una pieza clave para el periodista y que son la base de su trabajo, la gran aportación de la red social es, justamente, actuar de fuente para mejorar y facilitar la labor del profesional. Si se hace un uso óptimo, no hay por qué dudar de la fiabilidad de Twitter. Esta investigación ha demostrado, por ejemplo, que se reenvían los mensajes de la propia fuente protagonista de la noticia, fuentes de primera mano, creíbles y veraces. Igualmente, se puede obtener mucha información si se elige seguir cuentas con garantía y calidad. Buenos contactos se traducen en buenas fuentes, y así lo creen los periodistas vascos. A través de los contactos, el periodista se crea su propio universo, un universo muy selectivo de lo que recibe en Twitter, íntimamente ligado con aquello sobre lo que escribe. En este sentido, es una herramienta apropiada para que el periodista vaya configurando una agenda propia y diferenciada, especializada en un área temática concreta.

Asimismo, hemos observado que los periodistas siguen a multitud de medios de comunicación y profesionales del sector. Manejan diferentes perspectivas e informaciones sobre aquello que les interesa profesionalmente $\mathrm{y}$, en consecuencia, se alimentan del trabajo de los demás periodistas, que a su vez se complementa con el 
trabajo de uno mismo. Para enriquecer su propio trabajo, conviene que el grupo al que el periodista ha decidido seguir sea un universo, en su concreción y especialización, variado y abierto, que evite una visión unilateral y reducida de la realidad.

El rol activo del periodista en Twitter se traduce en la difusión de contenidos, la cobertura de acontecimientos, la información y la opinión. En todas estas funciones, ejerce de filtro para sus seguidores. Reflejo de ello es que el $41 \%$ de todos los mensajes profesionales enviados por los periodistas vascos son retweets; es decir, son el resultado de una selección de mensajes de terceros y posterior difusión por parte de los periodistas. Ese dato constata que en Twitter lo que importa es lo que el periodista tiene que ofrecer a los demás, sea de producción propia o ajena. Los periodistas se nos presentan como mediadores que seleccionan, orientan, dinamizan, guían, gestionan, filtran, difunden, recomiendan... lo que fluye en la Red. Tal y como se ha visto, muchas veces es una selección y un filtro especializado en el terreno que controla cada periodista. Al fin y al cabo, el filtro cobra más valor como filtro especializado y cualificado y, de alguna manera, ejerce de servicio a la carta para el lector, que sigue a aquellos periodistas centrados en los temas que le interesen.

Como filtro y mediador, el periodista adquiere también una función muy importante en Twitter: la gestión y organización del conocimiento que circula por la Red. Seleccionar y difundir adecuadamente la información, la opinión, el análisis y la reflexión existente en la Red es, al fin y al cabo, seleccionar y difundir el conocimiento particular que se convierte en conocimiento compartido. Twitter ayuda a situar el contexto, al análisis, a seleccionar opinión cualificada, a contrastar la información y a separar lo relevante de lo accesorio. Y, sobre todo, aporta un valor añadido para conseguir un trabajo de mayor calidad: interacción.

Los comunicadores vascos, conscientes de la importancia y de las implicaciones de la interacción en Twitter, aplican la 'ética de los enlaces', siendo generosos y difundiendo lo que los demás tienen que aportar; atienden las dudas, preguntas, aclaraciones y correcciones del resto; debaten con otros usuarios; mantienen la relación con sus fuentes también a través de los mensajes no profesionales... y sustentan un feedback de ida y vuelta. El rol activo de la audiencia en Twitter influye en la producción, realización, reelaboración y difusión del contenido periodístico que publican los periodistas vascos.

Por una parte, la red social sirve como pulsómetro de la labor del periodista: éste testea el interés de los temas entre sus seguidores, observa las reacciones que han recibido sus artículos, y calcula los retweets y favoritos que consiguen sus mensajes. Sin embargo, el periodista o el medio en cuestión haría mal si su única forma de medición de la opinión pública fuera Twitter. La red social es una herramienta más, pero ni todos los lectores están en Twitter, ni todos los que están se pronuncian sobre los contenidos producidos por los profesionales.

Por otra parte, aporta otro valor añadido al trabajo periodístico: la colaboración. Sacar el mayor provecho a la audiencia en la red social no supone exprimirla en beneficio propio, sino apostar por una colaboración mutua en beneficio de una información y una comunicación más completa. Uno de los ejemplos más claros de periodismo colaborativo lo hemos encontrado en la cobertura en directo de acontecimientos. Y una vez más, la función del periodista se convierte en gestionar adecuadamente toda esa información descentralizada, utilizarla para completar la suya 
y ofrecérsela a la audiencia. Es más, gestiona no solo el contenido producido en la red social por la audiencia, sino a la propia audiencia. Es decir, si tanto para crear y fidelizar a una comunidad de lectores en torno al medio, como para aprovechar su colaboración, es imprescindible escuchar y aprender de la audiencia, interaccionar con ella, conversar con ella, entonces no basta con dejar que se exprese, sino que hay que incentivar su participación, dinamizarla, fomentarla. Así, se ha visto cómo los periodistas promueven debates, lanzan preguntas a sus seguidores o les invitan a participar en los contenidos del medio. Este rol de dinamizador, orientador e incluso guía entre la audiencia se ajusta perfectamente a la posición influyente que adquiere el periodista en Twitter, puesto que, siendo realistas, aún se está lejos del ideal de la comunicación 2.0, horizontal, multidireccional y participativa, donde todos dialogan con todos de igual a igual. Twitter es una herramienta que cumple con esas características, pero las oligarquías participativas existen igualmente en la red social y no todos tienen el mismo grado de influencia en la esfera pública de Twitter. Los periodistas y lo que éstos tengan que decir, al igual que las cuentas corporativas de los medios, siguen teniendo un lugar destacado en la red social. Sin olvidar, eso sí, que esa posición hay que ganársela y trabajársela, cuidando la credibilidad, el buen periodismo, la profesionalidad, el valor añadido...

La interacción tuitera, por último, ayuda a reforzar la comunidad, en tanto que facilita que se cree una relación o un vínculo entre el periodista y sus lectores, beneficioso para ambos (y por extensión, también para el medio). El usuario/lector se siente en Twitter con derecho a opinar, corregir, preguntar, consultar... a los periodistas, lo cual ayuda a que se sienta parte de la comunidad que rodea al medio (o al periodista, y por extensión, al medio; o, en los mejores casos, a ambos, medio y periodista, que trabajan conjuntamente y en la misma dirección, según lo analizado). En Twitter, los periodistas parecen alimentar comunidades unidas en lo esencial (mediante un periodismo comprometido basado en valores y opiniones muy tajantes), pero variadas y participativas en el contenido, gracias a las identidades propias y a las diferentes miradas que circulan a su alrededor y con las que interaccionan. Al fin y al cabo, el medio construye su comunidad a partir de su posición en el mundo, de su mirada respecto a lo que le rodea, compartiendo necesidades, demandas, criterios, identidades y principios con los lectores que 'se unen' a su comunidad. De ahí la relevancia de las opiniones en la red social. Muchos lectores identificados, leales y fieles son sinónimo de una comunidad fuerte y sólida, fundamental para la supervivencia (también económica) de cualquier proyecto comunicativo.

El periodismo comprometido y la opinión cualificada destacan en la actividad tuitera de los periodistas vascos. Se ha detectado que los redactores sienten menos presión escribiendo en la red social que escribiendo en el periódico para el que trabajan. No hay más que ver algunos ejemplos recogidos en los resultados que difícilmente veríamos publicados en ningún medio. Así, en Twitter se ha encontrado un periodismo claramente beligerante, directo, sin cortapisas, tajante y que, en tanto que tiene éxito entre los usuarios, sirve para conectar con la gente y fortalecer la comunidad (en torno al medio) de aquellos que comparten los mismos principios. Unido a ello, el lenguaje más desenfadado y experimental de los periodistas en Twitter, así como la utilización de los recursos que ofrece la herramienta, generan una nueva narrativa 
periodística y aportan creatividad, frescura y originalidad a los contenidos periodísticos y a la presentación de los mismos.

Gracias en parte al uso de los recursos que ofrece la red social, los periodistas demuestran además que aunque Twitter aún depende y se alimenta de otros formatos, también es capaz de informar, opinar o cubrir la actualidad por sí misma. Hay producción, realización y difusión periodística que se crea, elabora y divulga exclusivamente en y para Twitter; una muestra destacable es la cobertura profesional de acontecimientos en directo.

Si tomamos en consideración los antecedentes empíricos expuestos en este artículo, los periodistas hacen un uso de Twitter más variado, creativo y provechoso que el que hacen las cuentas corporativas de los medios de comunicación. No obstante, el uso podría ser mejorable, no tanto en la variedad de funciones que desarrollan en la red social, sino en la profundización de las mismas: por ejemplo, dinamizando más la relación con sus lectores, aprovechando mejor los recursos que ofrece Twitter, elaborando una agenda propia, coordinando su actividad en la red social con la de sus compañeros de redacción y con la de la cuenta del periódico a través de libros de estilo, manuales o pautas básicas. En definitiva, interactuando más con el resto, atendiendo, escuchando, aprendiendo, colaborando, siendo transparentes y generosos, abiertos a la crítica y al disenso... porque la información y la comunicación periodística será una información y comunicación basada en el diálogo, o no será.

\section{Referencias bibliográficas}

AIMC (2014). Internet supera por primera vez el $60 \%$ de promedio de acceso diario. AIMC. Recuperado de http://www.aimc.es/2\%C2\%AA-Ola-EGM-Internetsupera-por.html

Asociación Española De Economía Digital (2010). Estudio uso de Twitter en España. Barcelona: Asociación Española de Economía Digital. Recuperado dehttp://www. adigital.org/emailing/2010/docs/adigital_Estudio_Uso_Twitter_enEspana_2010.pdf

Broersma, M., y Graham, T. (2013). Twitter as a news source: How Dutch and British newspapers used tweets in their news coverage, 2007-2011. Journalism Practice, 7, 446-464. doi: http://dx.doi.org/10.1080/17512786.2013.802481

Campos, F. (2008). Las redes sociales trastocan los modelos de los medios de comunicación tradicionales. Revista Latina de Comunicación Social, 63, 287-293. Recuperado de http://www.revistalatinacs.org/_2008/23_34_Santiago/Francisco_Campos.html

CIES (2013). Estudio de la Audiencia de Medios de Comunicación en la C. A. de Euskadi y Navarra. CIES. Recuperado de http://www.ciessl.com/audienciamedios.htm

Cobos, T. L. (2010). Twitter como fuente para periodistas latinoamericanos. Razón y Palabra, 73. Recuperado de http://www.razonypalabra.org.mx/N/N73/ Varia73/33Cobos_V73.pdf 
Corbetta, P. (2007). Metodología y técnicas de investigación social. Madrid: McGraw Hill.

Diezhandino, M. P. (coord.) (2012). El periodista en la encrucijada. Barcelona: Ariel-Fundación Telefónica.

Doval, M. (2014). Spanish and Portuguese journalists on Twitter: best practices, interactions and most frequent behaviors. Observatorio Journal, 8(3), 169-182. Recuperado de http://obs.obercom.pt/index.php/obs/article/view/730/679

Eford, A., Linke, M., y Messner, M. (2011). Shoveling tweets: An analysis of the microblogging engagement of traditional news organizations. P12 International Symposium on Online Journalism. Recuperado de http://online.journalism.utexas.edu/2011/papers/Messner2011.pdf

EGM (2014). Resumen general de resultados: Octubre de 2013 a Mayo de 2014. EGM. Recuperado de www.aimc.es/spip.php?action=acceder_document\&arg=2590\&cle =220f931df0e4b91629bc5367091ff4bf1baba1b9\&file=pdf\%2Fresumegm214.pdf

EUSTAT (2013). Periódicos en la C.A. de Euskadi. 2012. Eustat. Recuperado de http://www.eustat.es/elementos/ele0009500/ti_Peridicos_en_la_CA_de_Euskadi_2012/tb10009596_c.html\#axzz3Df91bmAp

GAD3 (2012). Informe 2012. Medios de Comunicación en Redes Sociales. GAD3. Recuperado de http://www.gad3.com/docs/docs/000103_doc_TA-120601\%20 Informe $\% 20 \mathrm{de} \% 20$ redes $\% 20 \mathrm{y} \% 20$ medios.pdf

García-De-Torres, E., Yezers'Ka,L., Rost,A.,Calderín,M., Edo,C., Rojano,M.,Said, E.,Jerónimo,P.,Arcila,C., Serrano,A.,Badillo,J., y Corredoira,L. (2011).Eluso de Twitter y Facebook por los medios iberoamericanos. El Profesional de la Información,20(6),611-620.doi:http://dx.doi.org/10.3145/epi.2011.nov.02Recuperadode http://www.academia.edu/1477639/El_uso_de_Twitter_y_Facebook_por_los_ medios_iberoamericanos

Herrera,S.,yRequejo,J.L.(2011).Difundirinformación,principalusodelos diarios generalistas españolesenTwitter.Textual \& Visual Media,4,149-182.Recuperadode http://www.textualvisualmedia.com/images/revistas/04/Difundir\%20informacin.pdf

IAB SPAIN (2010). II Estudio sobre Redes Sociales en Internet. Madrid: IAB Spain.

Kwak, H.; Lee, C; Park, H., y Moon, S. (2010). What is Twitter, a social network or a news media? 19th international conference on World Wide Web. North Carolina: Raleigh, 591-600. doi: 10.1145/1772690.1772751

Lajas, J. (2013). Informe de Oriella sobre periodismo digital: crece el uso de Twitter entre los periodistas. Periodismo Ciudadano. Recuperado de http://www.periodismociudadano.com/2013/06/18/informe-de-oriella-sobre-periodismo-digitalcrece-el-uso-de-twitter-entre-los-periodistas/

Lara, T. (2008) La nueva esfera pública. Los medios de comunicación como redes sociales. Revista Telos, 76. Recuperado de http://sociedadinformacion.fundacion.telefonica.com/telos/articulocuaderno. asp@idarticulo\%3D9\&rev\%3D76.htm

Noguera, J. M. (2010). Redes sociales como paradigma periodístico. Medios españoles en Facebook. Revista Latina de Comunicación Social, 65, 176-186. Recuperado de http://www.revistalatinacs.org/10/art/891_UCAM/13_JM_Noguera.html 
ORIELLA PR NETWORK (2011). Oriella Digital Journalism Study 2011. Oriella PR Network. Recuperado de http://orielladigitaljournalism.com/files/assets/ downloads/publication.pdf

Oviedo Anchundia, M.E., y Ulloa, P. L. (2015). Análisis de la Interacción en Twitter, entre los televidentes y los noticieros matinales en la ciudad de Guayaquil. Innova Research Journal, 1(09), 58-76. Recuperado de http://www.journaluidegye. com/magazine/index.php/innova/article/view/52/55

Said-Hung, E., Serrano-Tellería, A., García de Torres, E., Calderín, M., Rost, A., Arcila-Calderón, C., Yezers'ka, L., Edo Bolós, C., Miladys Rojano, P.J., y Sánchez Badillo, J. (2013). Ibero American Online News Managers' Goals and Handicaps in Managing Social Media. Television and New Media. doi: 10.1177/1527476412474352 Recuperado de http://repositorio.ismt.pt/bitstream/123456789/371/1/Ibero-American\%200nline\%20News\%20Managers $\% 27 \% 20$ Goals\%20and\%20Handicaps\%20in\%20Managing.pdf

Santos, E. (2016). Las cifras de Twitter en su décimo aniversario. El Huffington Post. Recuperado de http://www.huffingtonpost.es/2016/03/21/cifras-twitter_n_9496074.html

Social Times (2012). How Social Media Is Replacing Traditional Journalism As A News Source. Recuperado de http://www.adweek.com/socialtimes/ social-news/462734

Vis, F. (2013). Twitter as a reporting tool for breaking news: journalists tweeting the 2011 UK riots. Digital Journalism, 27-47. doi: http://dx.doi.org/10.1080/216708 11.2012.741316. Recuperado de http://www.tandfonline.com/doi/pdf/10.1080/2 1670811.2012.741316?needAccess=true 